\title{
Immunochemical Analysis of Uridine Diphosphate-Glucuronosyltransferase in Four Patients with the Crigler-Najjar Syndrome Type I
}

Helmuth H. G. van Es, Bart G. Goldhoorn, Marianne Paul-Abrahamse, Ronald P. J. Oude Elferink, and Peter L. M. Jansen Division of Gastroenterology, Academic Medical Center, 1105 AZ Amsterdam, The Netherlands

\begin{abstract}
The functional heterogeneity of uridine diphosphateglucuronosyltransferase (UDPGT) and its deficiency in human liver were investigated. The monoclonal antibody (MAb) WP1, which inhibits bilirubin and phenol-glucuronidating activity, was used to immunopurify UDPGTs from human liver. Purified UDPGTs were injected into mice to obtain new MAbs. Immunoblotting of microsomes with MAb HEB7 revealed at least three polypeptides in liver $(56,54$, and $53 \mathrm{kD})$ and one in kidney (54 kD). In liver microsomes from four patients (A, B, C, and D) with Crigler-Najjar syndrome type I (CN type I), UDPGT activity towards bilirubin was undetectable (A, B, C, and D) and activity towards phenolic compounds and 5-hydroxytryptamine either reduced (A and B) or normal (C and D). UDPGT activity toward steroids was normal. Immunoblot studies revealed that the monoclonal antibody WP1 recognized two polypeptides (56 and $54 \mathrm{kD}$ ) in liver microsomes from patient $A$ and none in patient $B$. With HEB7 no immunoreactive polypeptides were seen in these two patients. Patient $\mathrm{C}$ showed a normal banding pattern and in patient $D$ only the 53-kD band showed decreased intensity. These findings suggest considerable heterogeneity with regard to the expression of UDPGT isoenzymes among CN type I patients. (J. Clin. Invest. 1990. 85:1199-1205.) glucuronidation • unconjugated hyperbilirubinemia $\cdot \operatorname{monoclonal}$ antibody $\bullet$ immunopurification • human liver
\end{abstract}

\section{Introduction}

Uridine diphosphate-glucuronosyltransferase (UDPGT, ${ }^{1}$ EC 2.4.1.17) is a membrane-bound enzyme system concentrated in the lipid bilayer of the endoplasmic reticulum in hepatocytes and cells of intestine, kidney, and other tissues (1). It catalyzes the transfer of glucuronic acid from uridine $5^{\prime}$-di-

Part of this work was presented in November 1988, April 1989, and May 1989 at the AASLD annual meeting in Chicago, the Bilirubin Workshop in Trieste, and American Gastroenterology Association Digestive Disease Week in Washington DC, respectively.

Address reprint requests to Dr. van Es, Albert Einstein College of Medicine, Liver Research Center, Ulmann Building, Room 625, 1300 Morris Park Avenue, Bronx, 10461.

Received for publication 24 July 1989 and in revised form 1 December 1989.

1. Abbreviations used in this paper: $\mathrm{CN}$ type I, Crigler-Najjar syndrome type I; 5-HT, 5-hydroxytryptamine; 4-MU, 4-methylumbelliferone; PNP, paranitrophenol; UDPGT, uridine diphosphate-glucuronosyltransferase.

J. Clin. Invest.

(c) The American Society for Clinical Investigation, Inc.

0021-9738/90/04/1199/07 \$2.00

Volume 85, April 1990, 1199-1205 phosphate-glucuronic acid to compounds of either endogenous or exogenous origin such as bilirubin, steroids, phenolic compounds, and a wide range of different drugs.

Patients with the Crigler-Najjar syndrome type I (CN type I) have an inheritable complete deficiency of UDPGT activity towards bilirubin which results in a severe nonhemolytic unconjugated hyperbilirubinemia (2). These patients often die of kernicterus in infancy or early adulthood. The mutant Gunn rat also lacks hepatic UDPGT activity for bilirubin and forms an animal model for the $\mathrm{CN}$ type $\mathrm{I}(3,4)$. In addition, UDPGT activity towards phenolic compounds and digitoxigenin monodigitoxoside has been reported to be decreased in the Gunn rat (5-7) and in CN type I liver (8).

Most of the current knowledge on various aspects of UDPGT is based on studies of the enzyme system present in rat liver. The differential induction and development profiles of substrate-specific UDPGT activities are indirect indications for the existence of multiple isoenzymes of UDPGT in the rat (9-11). Chromatofocusing of rat liver microsomal UDPGT activities revealed the existence of at least five different isoenzymes (12-14), and recently two more isoenzymes have been purified $(15,16)$. Two of these isoenzymes are a bilirubin- and phenol-UDPGT. Furthermore, structural information has been obtained by cDNA cloning of several isoenzymes (17-20). Less information is available on the multiplicity of UDPGT in human tissues. Purification of two isoenzymes and the cloning of two cDNAs has been reported (21-23). Recently it has been shown that 4-methylumbelliferone (4-MU), a substrate for the purified and cloned human liver phenolUDPGT, could not inhibit the glucuronidation of bilirubin by human liver microsomes (24). This suggests that in human liver separate bilirubin- and phenol-UDPGT isoenzymes also exist.

Monoclonal antibodies are a powerful tool for the characterization of heterogeneous enzyme systems (25). The first reported monoclonal antibody against UDPGT, which is designated WP1, was produced against UDPGT of human origin (26). This antibody inhibits the glucuronidation of bilirubin, paranitrophenol (PNP), and 4-MU but not that of steroids like testosterone. Furthermore, several polypeptides reacting with this antibody are visualized by immunoblotting experiments after SDS-PAGE (27).

In the present study we have used this and a new monoclonal antibody to characterize the defect in livers from several $\mathrm{CN}$ type I patients.

\section{Methods}

Materials. Cyanogen bromide-activated Sepharose 4B beads were purchased from Pharmacia (Uppsala, Sweden). Goat anti-mouse and goat anti-rabbit antibodies conjugated with either horseradish peroxidase or alkaline phosphatase were from Bio-Rad Laboratories (Richmond, CA). Nitrocellulose membranes were from Schleier \& Schull (Kassel, FRG). All reagents used were of analytical quality. 
Tissue samples. Normal human liver was obtained from surgical resection specimens. Human kidney specimens came from autopsy performed within $12 \mathrm{~h}$ after death. Liver material of four $\mathrm{CN}$ type I patients was obtained after orthotopic liver transplantation (patients A, B, C, and D). Some clinical data of these patients are given in Table I. All human specimens were stored at $-70^{\circ} \mathrm{C}$.

Isolation of microsomes and homogenates from human liver and kidney was performed as previously described (25). The microsomal pellets were resuspended in $50 \mathrm{mM}$ Tris- $\mathrm{HCl}, \mathrm{pH} 7.8,250 \mathrm{mM}$ sucrose, and $2 \mathrm{mM}$ EDTA and frozen as aliquots at $-20^{\circ} \mathrm{C}$ until use within $3 \mathrm{mo}$.

Enzyme assays. Glucuronidation of bilirubin, PNP, 4-MU, 5-hydroxytryptamine (5-HT), estrone, $\beta$-estradiol, androsterone, testosterone, and estriol was measured as described elsewhere $(21,28-30)$ and NADPH-cytochrome $c$ reductase activity according to Williams and Kamin (31).

Immunoprecipitation of human UDPGT activities. Mouse ascites proteins with a high titer of WP1 antibody were covalently coupled to cyanogen bromide-activated Sepharose $4 \mathrm{~B}$ beads as prescribed by the manufacturer. The coupled beads were suspended in phosphate-buffered saline (PBS, $160 \mathrm{mM} \mathrm{Na}^{+}, 9.2 \mathrm{mM} \mathrm{HPO}_{4}^{2-}, 1.3 \mathrm{mM} \mathrm{H}_{2} \mathrm{PO}_{4}^{-}, 140$ $\mathrm{m} \mathrm{M} \mathrm{Cl}^{-}$, $\mathrm{pH} 7.4$ ) containing $0.05 \% \mathrm{wt} / \mathrm{vol}$ sodium azide and stored at $4^{\circ} \mathrm{C}$ until further use. Immunoprecipitation of UDPGT activity towards PNP and 4-MU was carried out with human liver microsomes, after solubilization with Emulgen 911 (Kao Atlas Ltd., Tokyo, Japan) Different amounts of immobilized monoclonal antibody (WPI) were added and incubated, rotating end-over-end at $4{ }^{\circ} \mathrm{C}$ for $2 \mathrm{~h}$. After centrifugation, UDPGT activity was measured in the supernatant.

Immunopurification of human UDPGT. Human liver or kidney microsomes were solubilized in $1 \%$ Triton X-100, $50 \mathrm{mM}$ Tris- $\mathrm{HCl}$ pH 7.8, $250 \mathrm{mM}$ sucrose, and $2 \mathrm{mM}$ EDTA for $30 \mathrm{~min}$ at $4^{\circ} \mathrm{C}$. Unsolubilized material was pelleted by centrifugation at $40,000 \mathrm{~g}$ for $15 \mathrm{~min}$. The supernatant was applied to a column of immobilized WP1 at a flow rate of $1 \mathrm{ml} / \mathrm{min}$. After immunoabsorption of UDPGT the column was washed sequentially with five bed volumes of $50 \mathrm{mM}$ Tris$\mathrm{HCl}, \mathrm{pH} 7.8,250 \mathrm{mM}$ sucrose, $2 \mathrm{mM}$ EDTA, $1 \%$ Triton $\mathrm{X}-100$, and five bed volumes of the same buffer but containing $0.1 \%$ Triton X-100. Subsequently, UDPGT immunoreactivity was eluted with $2 \mathrm{M} \mathrm{MgCl}_{2}$,

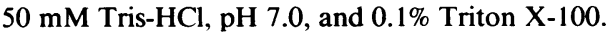

ELISA. The elution of UDPGT immunoreactivity from the WP1 immunoaffinity column was detected by means of an ELISA. The eluted fractions were diluted 25-fold with PBS and applied to ELISA plate wells and incubated for $16 \mathrm{~h}$ at $4^{\circ} \mathrm{C}$. Excess protein binding sites were blocked with $1 \%$ BSA in PBS for $45 \mathrm{~min}$. After washing six times with tap water containing $0.05 \%$ Tween 20 and two times with PBS containing $0.05 \%$ Tween 20, WP1 ascites was added at 1:5,000 dilution in PBS containing $0.05 \%$ Tween 20 , and $1 \%$ BSA. Antibody binding was detected by incubation with horseradish peroxidase-conjugated goat anti-mouse $\mathrm{Ig}(\mathrm{H}+\mathrm{L})$ (Bio-Rad Laboratories), followed by assay

Table I. Clinical Data of the Four CN Type I Patients

\begin{tabular}{lccccc}
\hline & & \multicolumn{4}{c}{ Patient } \\
\cline { 3 - 6 } & Control & A & B & C & D \\
\hline $\begin{array}{l}\text { Age }(y r) \\
\begin{array}{l}\text { Gender } \\
\text { Average serum bilirubin } \\
(\mu \text { mol/liter })\end{array}\end{array}$ & M/F & F & M & F & F \\
& $<17$ & 250 & $?$ & 428 & 420 \\
\end{tabular}

Average serum bilirubin is given as the total concentration. No effect of phenobarbital treatment on the total serum bilirubin concentration was observed.

Abbreviations: F, female; $M$, male. of the bound peroxidase activity by using 3,3', 5,5'-tetramethylbenzidine as a substrate. The amount of product formed was measured spectrophotometrically at $450 \mathrm{~nm}$. Positive fractions were pooled and dialyzed against PBS containing $0.1 \%$ Triton X-100. The immunopurified UDPGT was stored in aliquots at $-20^{\circ} \mathrm{C}$ until further analysis.

Preparation of monoclonal and polyclonal antibodies. Before immunization, the immunopurified UDPGT was concentrated by means of precipitation with $10 \%$ TCA (at $4^{\circ} \mathrm{C}$ for $10 \mathrm{~min}$ ) followed by washing the pellet with aceton at $-20^{\circ} \mathrm{C}$. Subsequently, the pellet was resolubilized in PBS containing $0.1 \%$ SDS. Protein was determined by the method of Bradford (32). BALB/c mice were immunized by intraperitoneal injection of $25 \mu \mathrm{g}$ of immunopurified human UDPGT in Freund's complete adjuvant. After 1 wk a similar immunization took place but in Freund's incomplete adjuvant. 3 wk later intravenous injections of $70 \mu \mathrm{g}$ of immunopurified human UDPGT were given in PBS. $4 \mathrm{~d}$ after this booster the mice were killed and the spleen was removed. Spleen cells $\left(40 \times 10^{6}\right)$ were fused with $\mathrm{sp} 2 / 0$ myeloma cells $\left(8 \times 10^{6}\right)$ in the presence of $38 \%$ polyethylene glycol (PEG 4000) for 1 min. The cells were washed with DME medium and cultured in DME supplemented with $10 \%$ (vol/vol) fetal calf serum, $50 \mu \mathrm{M} 2$-mercaptoethanol, $200 \mu \mathrm{g} / \mathrm{ml}$ streptomycin, $200 \mathrm{U} / \mathrm{ml}$ penicillin, $100 \mu \mathrm{M}$ hypoxanthine, $0.4 \mu \mathrm{M}$ aminopterine, and $16 \mu \mathrm{M}$ thymidine. The hybridomas were cultured in this medium for $1 \mathrm{wk}$ after which the aminopterine was left out and after $3 \mathrm{wk}$ the hypoxanthine and thymidine were left out. Hybridoma media were screened for reactivity with immunopurified human UDPGT in ELISA as described above. Positive wells were cloned and subcloned until a stable positive clone was obtained. This clone was designated HEB7. Production of the antibody secreted by HEB7 was performed by injection of BALB/c mice intraperitoneally with $2 \times 10^{5}$ cells. After $10 \mathrm{~d}$ ascites was collected.

$S D S-P A G E$. SDS-PAGE and immunoblotting were carried out as described by Laemmli (33) and Towbin et al. (34). Immunoreactive polypeptides were detected with alkaline phosphatase-conjugated antibodies according to Blake et al. (35) modified by Promega Biotec (Madison, WI).

\section{Results}

Immunopurification of UDPGT and production of antibodies. The monoclonal antibody WP1 inhibits the glucuronidation of bilirubin, PNP, and 4-MU by detergent activated human liver microsomes up to, respectively, $67 \%, 75 \%$, and $55 \%$. The glucuronidation of testosterone, estrone, and phenolphthalein is not inhibited (26). To investigate whether WP1 could be used as a tool for preparative purification of UDPGT from human tissue, immunoprecipitation experiments were carried out with WP1 immobilized to Sepharose 4B beads. WP1 beads were able to precipitate $50 \%$ of the UDPGT activity towards PNP from Emulgen 911-solubilized microsomes. A similar fraction of activity towards 4-MU was precipitated (Fig. 1). Addition of a higher amount of WP1 did not increase the precipitation, indicating that the residual activity might represent an isoenzyme that does not react with this antibody. Using the monoclonal antibody WP1 a UDPGT-immunopurification procedure was developed. Triton X-100 solubilized human liver microsomes were applied to a column of Sepharose-immobilized WP1. Human liver UDPGTs were eluted with $2 \mathrm{M} \mathrm{MgCl}_{2}$. SDS-PAGE of the immunopurified human liver UDPGTs revealed that within the limits of resolution four polypeptides with a distinct, apparent molecular mass of $57,56,54$, and $53 \mathrm{kD}$ can be recognized (Fig. 2). The yield of this one-step procedure was $\sim 1 \mathrm{mg}$ of immunopurified UDPGT protein from $150 \mathrm{mg}$ of solubilized microsomal proteins. 

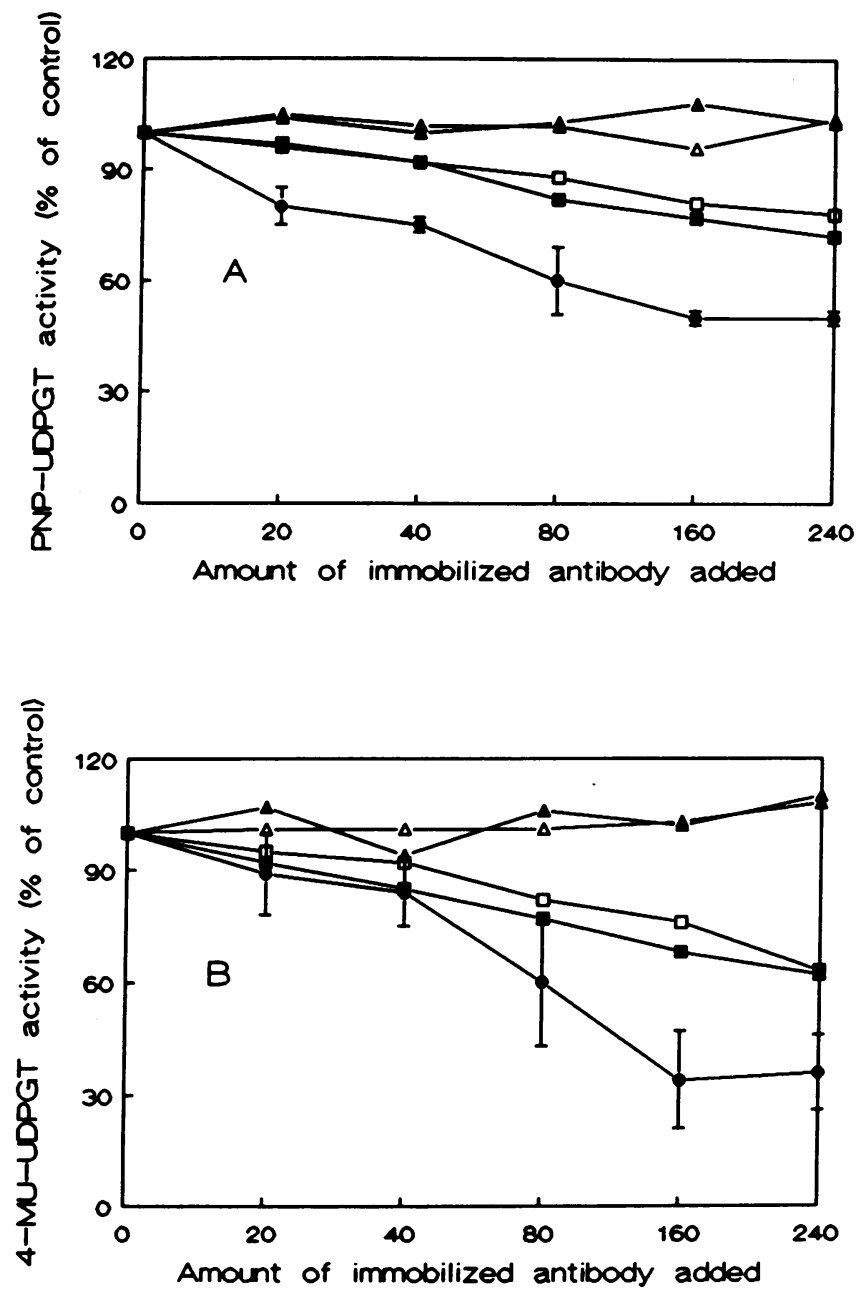

Figure 1. Immunoprecipitation of human hepatic UDPGT activity by immobilized WP1. Microsomes were solubilized with Emulgen 911 and incubated with different amounts of the immobilized antibody at $20^{\circ} \mathrm{C}$. The supernatants were analyzed for UDPGT activity toward $(A)$ PNP and $(B)$ 4-MU. The immunoprecipitation experiments were carried out with microsomes isolated from adult human liver ( $\bullet$ ) and from the liver of the CN type I patients A $(\Delta), B(\Delta), C$ $(\square)$, and $D(\square)$. Results of control human liver microsomes represent the mean \pm SD of three different experiments performed with microsomes isolated from three different control livers. Single representative experiments are given for the four patients.

Immunopurified human UDPGTs were injected into mice and rabbits to obtain new monoclonal and polyclonal antibodies. Screening and subsequent cloning of the hybrid cells resulted in a hybridoma clone HEB7, secreting an antibody that reacts in the ELISA with immunopurified UDPGT from human liver. The fractions obtained by the described procedure were also tested for their immunoreactivity with HEB7. The fractions that reacted with WP1 also reacted with HEB7. More importantly, HEB7 did not react with any of the polypeptides present in the run-through of the column, indicating that HEB7 reacts with no other polypeptides than those immunopurified on the WP1 column.

Characterization of UDPGT from four CN type I patients. Microsomes isolated from the livers of four patients with $\mathrm{CN}$ type I did not catalyze the glucuronidation of bilirubin. The

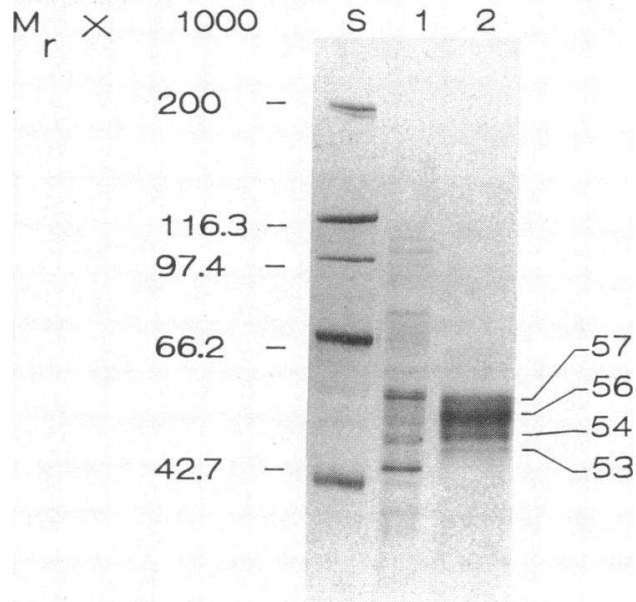

Figure 2. SDS-PAGE of crude microsomes and immunopurified UDPGT from human liver. The UDPGTs were immunopurified as described in Results. Microsomes were isolated as described in Methods. Proteins were electrophoresed on SDS/8\% polyacrylamide slab gels and visualized by Coomassie Blue staining. $S$, molecular mass markers: $200 \mathrm{kD}$ (myosin), $116.3 \mathrm{kD}$ ( $\beta$-galactosidase [Escherichia coli]), $97.4 \mathrm{kD}$ (phosphorylase $\mathrm{B}$ ), $66.2 \mathrm{kD}$ (bovine serum albumin), $42.7 \mathrm{kD}$ (ovalbumin); lane $1,20 \mu \mathrm{g}$ of human liver microsomes; lane 2, $10 \mu \mathrm{g}$ of WPI immunopurified human liver UDPGT.

activity towards PNP, 4-MU, and 5-HT was decreased in microsomes from patients $\mathrm{A}$ and $\mathrm{B}$ but not in microsomes from patients $C$ and $D$. In all patients glucuronidation of estriol, estrone, testosterone, and androsterone was within the range of control values (Table II). As a microsomal marker and test for the quality of the livers NADPH cytochrome $c$ reductase activity was measured. No significant difference between controls and patients could be observed. The significance of the lowered activity towards PNP and 4-MU in patients A and B was supported by immunoprecipitation experiments: no UDPGT activity towards PNP and 4-MU could be precipitated by WP1 (Fig. 1). However, the normal activity in patients $\mathrm{C}$ and $\mathrm{D}$ could be precipitated though to a lesser extent as in controls (Fig. 1).

The defect in $\mathrm{CN}$ type I patients was analyzed further by immunoblot analysis. Total homogenates from normal human liver and livers from the four $\mathrm{CN}$ type I patients were subjected to SDS-PAGE followed by blotting of the resolved proteins to nitrocellulose. The monoclonal antibody WP1 was used as antibody probe. Within the limits of resolution, normal liver revealed at least four immunoreactive polypeptides of $57,56,54$, and $53 \mathrm{kD}$ (Fig. 3, lanes $1-3$ ). The difference in staining intensity between the three control preparations is assumed to be caused by individual variation in the expression of UDPGTs. This is in accordance with the high variation in UDPGT activities found in control livers (see Table I).

In patient $A$ only two bands were visible (56 and $54 \mathrm{kD}$ ) and with strongly decreased intensity. In patient $B$ none of these polypeptides were detectable. Patient $\mathrm{C}$ and $\mathrm{D}$ showed a different picture: patient $\mathrm{C}$ showed a pattern similar to controls and in patient D only the lower bands (53 and $54 \mathrm{kD}$ ) were decreased in staining intensity.

When microsomes instead of homogenates were used the following picture emerged with patient A: WP1 recognized with decreased staining intensity a $56-$ and $54-\mathrm{kD}$ band but the 


\begin{tabular}{|c|c|c|c|c|c|}
\hline & \multirow{2}{*}{$\begin{array}{l}\text { Controls } \\
(n=5)\end{array}$} & \multicolumn{4}{|c|}{ CN type I patient } \\
\hline & & A & B & $\mathrm{C}$ & D \\
\hline Bilirubin ( $\mathrm{pmol} / \mathrm{min}$ per $\mathrm{mg}$ ) & $290 \pm 155$ & UD & UD & UD & UD \\
\hline PNP $(\mathrm{nmol} / \mathrm{min}$ per $\mathrm{mg})$ & $40 \pm 18$ & 13 & 4.9 & 44 & 50 \\
\hline 4-MU ( $\mathrm{nmol} / \mathrm{min}$ per $\mathrm{mg})$ & $20 \pm 3$ & $4^{*}$ & $4^{*}$ & 19 & 19 \\
\hline 5-HT ( pmol/min per mg) & $178 \pm 65$ & $30^{*}$ & $40^{*}$ & 240 & 150 \\
\hline Estriol $(\mathrm{nmol} / \mathrm{min}$ per $\mathrm{mg})$ & $12.8 \pm 1.5$ & 13.4 & 12.5 & 14.3 & 15.4 \\
\hline Estradiol ( $\mathrm{pmol} / \mathrm{min}$ per $\mathrm{mg}$ ) & $220 \pm 99$ & 103 & 95 & 169 & 143 \\
\hline Estrone $(\mathrm{pmol} / \mathrm{min}$ per $\mathrm{mg}$ ) & $72.6 \pm 15.4$ & 48 & 51 & 73 & 59 \\
\hline Testosterone $(\mathrm{pmol} / \mathrm{min}$ per $\mathrm{mg}$ ) & $200 \pm 150$ & 187 & 86 & 114 & 88 \\
\hline Androsterone $(\mathrm{nmol} / \mathrm{min}$ per $\mathrm{mg})$ & $3.1 \pm 1.1$ & 1 & 2.1 & 4.1 & 3.7 \\
\hline NADPH cytochrome $c$ reductase $(\mu \mathrm{mol} / \mathrm{min}$ per $\mathrm{mg}$ ) & $27 \pm 4.6$ & 31 & 24 & 35 & 37 \\
\hline
\end{tabular}

Bilirubin-, PNP-, 4-MU-, and 5HT-UDPGT activities are $\pm 0 \%, 10-100 \%$, and $20-100 \%$ of control values, respectively. UDPGT activities are given as values of glucuronide per minute per milligram of microsomal protein. Control values $\pm \mathrm{SD}$. Abbreviation: UD, undetectable. ${ }^{*}$ Significantly different from controls, $P<0.05$. Further assay conditions were as described in Methods.

lower 53-kD polypeptide could not be visualized (Fig. 4, panel I, lanes 2 and 3). No reaction was seen at all with HEB7 (Fig. 4, panel II, lanes 2 and 3). With microsomes of patient $B$ no UDPGTs could be visualized with either WP1 or HEB7 (Fig. 4, panels I and II, lanes 4 and 5). Polyclonal antibodies raised against immunopurified human liver UDPGTs also did not show any staining of these polypeptides in patient B (data not shown). Both MAbs recognized a single $54-\mathrm{kD}$ polypeptide in human kidney microsomes (Fig. 4, panels I and II, lane 6).

As stated above UDPGTs from patient A reacted differentially with our two monoclonal antibodies, which suggests a structural alteration in the polypeptides normally recognized by these antibodies. To verify this observation we purified UDPGTs from solubilized liver microsomes of patient A using a column of immobilized WP1. In an ELISA WP1 reacted normally with this UDPGT preparation. However, no immunological cross-reaction was observed when HEB7 was used as the antibody (Fig. 5). This again points to structural mutation of the WP1-recognized UDPGTs in this patient.

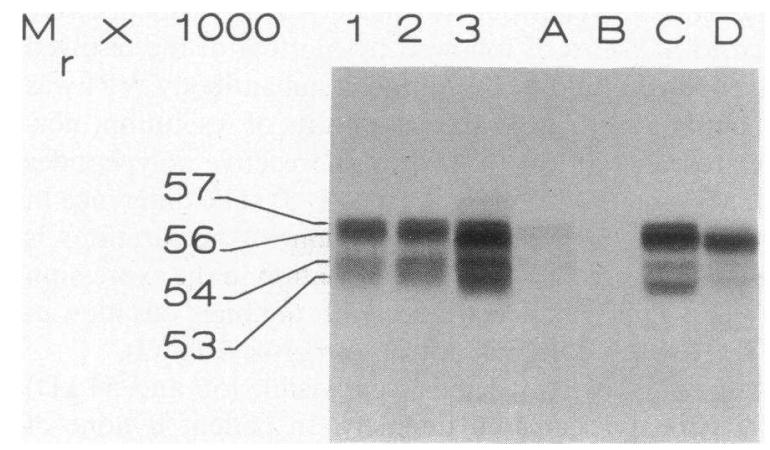

Figure 3. Immunological reaction of the monoclonal antibody WPI with homogenates made from three different control human livers: lanes 1,2 , and 3 (15 $\mu \mathrm{g}$ of protein) and the four $\mathrm{CN}$ type I patients: lanes $A, B, C$, and $D$ (25 $\mu \mathrm{g}$ of protein). Crude liver homogenates were electrophoresed in $8 \%$ SDS-polyacrylamide and transferred to nitrocellulose. Immunostaining was performed using the monoclonal antibody WP1.

\section{Discussion}

Immunopurification as reported in this paper is a powerful method for single-step, preparative purification of UDPGTs from human tissues. We were also able to obtain a pure 54-kD polypeptide from human kidney (data not shown). However, the method described here does not allow the purification of biologically active UDPGTs. This is probably due to extensive delipidation by the high concentrations of Triton X-100 used during chromatography $(36,37)$. By using the immunopurified human hepatic UDPGTs as antigen, a new antibody was obtained with characteristics different from the original monoclonal antibody WP1.

The specificity of the monoclonal antibody HEB7 was addressed by WP1 immunoaffinity chromatography. This clearly showed that the monoclonal antibody HEB7 only reacted with proteins bound by WP1 and not with the polypeptides in the runthrough of this column. In addition to this, the specificity of this monoclonal antibody for UDPGT was emphasized by the binding to partially purified phenol- and bilirubinUDPGT from rat liver microsomes. These polypeptides could not be detected in Gunn rat liver microsomes (data not shown).

Using WP1, in immunoblot analysis of normal human liver microsomes at least three polypeptides with a molecular mass of 56,54 , and $53 \mathrm{kD}$ were detected. When liver homogenates were used instead of microsomes the resolution was found to be much better resulting in an extra $57-\mathrm{kD}$ band. Using microsomes, this polypeptide is not or poorly separated from the 56-kD polypeptide. With HEB7, immunoblot analysis of normal human hepatic and renal microsomes revealed a pattern of immunoreactive polypeptides similar to WP1.

Renal microsomes showed a single $54-\mathrm{kD}$ polypeptide with both monoclonal antibodies and as bilirubin glucuronidating activity is absent in human kidney (27), the 53- or the $57-\mathrm{kD}$ polypeptide in human liver might represent the bilirubinUDPGT isoenzyme. Microsomes from human kidney are active towards phenolic compounds (27) and therefore the 54-kD polypeptide possibly represents a phenol-glucuronidating UDPGT isoenzyme. 


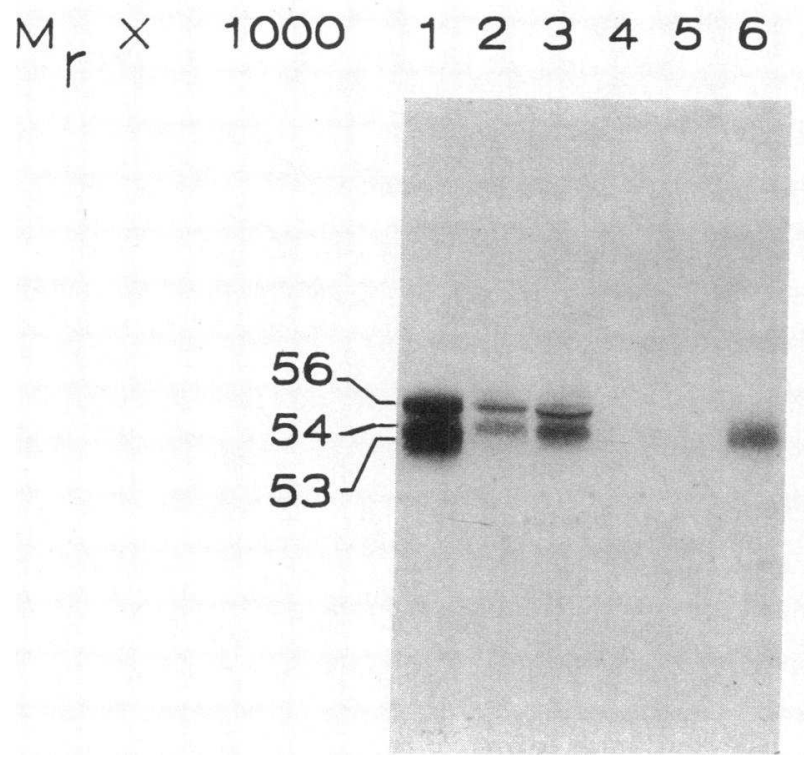

With WP1 at least two polypeptide bands were detectable in liver microsomes of patient $A$, whereas HEB7 showed no immunoreactivity at all in both Western blots and ELISA. In contrast to patient $\mathrm{A}$, in liver microsomes of patient $\mathrm{B}$ no staining of the polypeptides normally recognized by WP1, HEB7, or the polyclonal antibodies (data not shown) could be seen. Although the two patients differ in their reaction with the several antibodies, in both patients more than one UDPGT

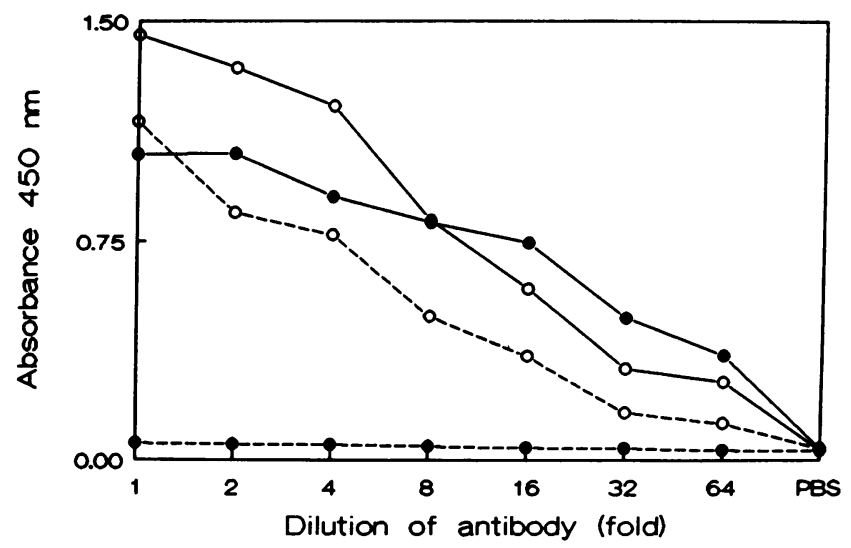

Figure 5. Immunological reaction of monoclonal antibodies WP1 and HEB7 with immunopurified UDPGT from human liver using the ELISA. Immunopurified UDPGTs from normal human liver (solid lines) and from the liver of $\mathrm{CN}$ type I patient $\mathrm{A}$ (dashed lines) were absorbed to the wells of microtiter plates. The plates were washed and incubated with twofold dilutions of the two different monoclonal antibodies starting with a 1:1,000 dilution of WP1 ascites (o) and a 1:100 dilution of HEB7 ascites (๑). Binding of antibody was detected as described in Methods. Both antibodies reacted specifically with UDPGTs from control human liver however no specific binding of the monoclonal antibody HEB7 to the WP1 immunopurified UDPGTs from $\mathrm{CN}$ type 1 patient $\mathrm{A}$ could be seen.

\section{6}

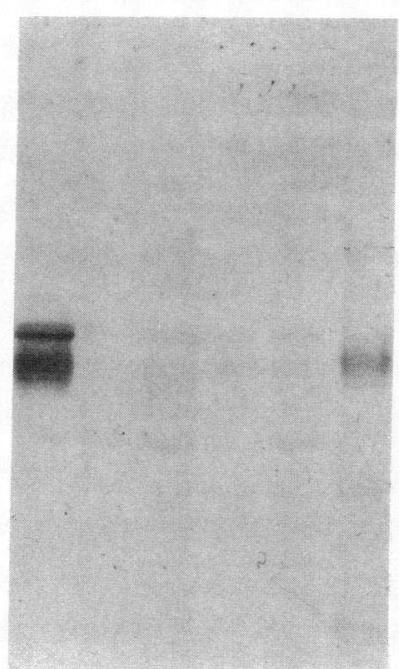

Figure 4. Immunological reaction of WP1 and HEB7 with microsomes isolated from human liver and kidney using Western blotting. Immunostaining was performed using the monoclonal antibodies WP1 (panel I) and HEB7 (panel II) as described in Methods. Lanes I- 1 and II- $I$, human liver microsomes $(10 \mu \mathrm{g})$; lanes I- 2 and $\mathrm{II}-2(20 \mu \mathrm{g})$ and I-3 and II-3 (40 $\mu \mathrm{g})$, liver microsomes $\mathrm{CN}$ type $\mathrm{I}$ patient A; lanes I-4 and II-4 (20 $\mu \mathrm{g})$ and $\mathrm{I}-5$ and II-5 $(40 \mu \mathrm{g})$, liver microsomes $\mathrm{CN}$ type I patient $\mathrm{B}$; lanes I-6 $(20 \mu \mathrm{g})$ and II-6 $(40 \mu \mathrm{g})$, human kidney microsomes. polypeptide is affected by the mutation underlying the defect in the CN type I. This agrees with the change in UDPGT activity for at least four of the five UDPGT substrates tested: bilirubin, PNP, 4-MU, and 5-HT. Although the activities for bilirubin, 5-HT, and 4-MU are significantly different from controls the decreased activity for PNP is not. The suggested decrease in activity for this substrate could reflect individual variation, known for normal human liver (21). However, the residual UDPGT activity towards PNP and 4-MU could not be precipitated by immobilized WP1 either from patient $A$ or B. This strongly supports that besides a deficient bilirubin glucuronidation, a phenol-glucuronidating UDPGT isoenzyme recognized by WP1 is defective in both $\mathrm{CN}$ type I patients. The nonprecipitable, residual phenol UDPGT activity probably represents one or more other isoenzymes not recognized by WP1 and not affected by the mutation in this patient.

Different from these results are the data for patients $\mathrm{C}$ and D. Only one of the measured UDPGT substrates is deficient: bilirubin. Furthermore, the polypeptide pattern as visualized with WP1 is similar or identical to that of controls. These data suggest that in patients $C$ and D only one UDPGT may be affected.

A possible explanation for the observations in patients A and $B$ is that bilirubin and phenolic compounds are conjugated by one isoenzyme, which shows microheterogeneity on SDS-PAGE and which is absent or mutated in these two patients. However, a number of considerations argue against this explanation: for rat liver it has been shown that the purified bilirubin-conjugating isoenzyme has little or no activity towards PNP and vice versa (13). Furthermore, glucuronidation of bilirubin takes place at carboxyl groups, whereas phenolic compounds like PNP are glucuronidated at aromatic hydroxyl groups. It is rather unlikely that conjugation of these different groups is catalyzed by the same active site. Furthermore, Miners et al. (24) could not show inhibition of bilirubin glucuronidation in human liver microsomes by 4-MU, a substrate 
for the purified and cloned phenol-UDPGT. Finally, as discussed above there is no bilirubin glucuronidation in human kidney while phenol conjugation is present (27) and precipitable with WP1 (data not shown). These arguments suggest that bilirubin and phenol glucuronidation in human liver is catalyzed by separate isoenzymes.

Abe et al. (38) were able to partially purify an isoenzyme from rat liver that is specific for 5-HT (38). For human liver the existence of a distinct 5-HT isoenzyme has been postulated $(39,40)$; based on these data the decrease of 5-HT UDPGT activity suggests that yet another isoenzyme is affected in patients $\mathrm{A}$ and $\mathrm{B}$.

From the results described in this study it can be concluded that at least two and maybe three different UDPGT isoenzymes are affected in patients $A$ and $B$. In contrast, in patients $\mathrm{C}$ and $\mathrm{D}$ only one isoenzyme appears to be affected. Recently liver tissue of a fifth patient was analyzed. The expression of UDPGTs was found to be similar to patient $B$.

A structural mutation in more than one isoenzyme could be explained by assuming different simultaneous mutations in more than one gene. Since in patient $\mathrm{A}$ the mutations in both polypeptides are identical namely absence of the epitope for HEB7, this would implicate that both genes carry very similar or identical mutations. Two possible genetic mechanisms have to be considered. Gene conversion of two different but homologous genes of which one is mutated is a possible explanation. This mechanism has been suggested for some cases of steroid$14 \alpha$-hydroxylase deficiency $(41,42)$ in which a normal and a pseudogene are involved. Another possible explanation for our observations is posttranscriptional and/or posttranslational modification of a single gene product which gives rise to bilirubin- and phenol-UDPGT isoenzymes. Recently an alternative splicing mechanism has been shown to exist for the cytochrome P-450-PB-7 gene. Two mRNAs encoding two different proteins are generated by this mechanism (43). Although the reported cDNAs do not clearly suggest such a mechanism, this possibility cannot be ruled out because a cDNA for bilirubin-UDPGT has not been cloned yet, either from human or rat liver cDNA libraries.

The results of patient $C$ and $D$ can be explained by each of the mechanisms discussed above: in case of separate genes only the bilirubin-UDPGT gene is mutated. In case of posttranscriptional and/or posttranslational modification only that part of the gene that is incorporated into the bilirubin isoenzyme may be mutated.

\section{Acknowledgments}

Specimens from normal human liver and kidney were kindly provided by Dr. J. L. G. Blauwgeers and Dr. A. Bosma, Department of Pathology, Academic Medical Center, Amsterdam; the livers of four patients with the CN type I were kindly provided by Dr. M. Sinaasappel, Sophia's Children's Hospital, Rotterdam; Dr. E. R. Gordon, Liver Unit Study, Yale Medical School, New Haven, CT; and Dr. Rod Markin, University of Nebraska Medical Center, Omaha, NE. We gratefully acknowledge the valuable discussions with Professor J. M. Tager, Department of Biochemistry, University of Amsterdam.

\section{References}

1. Dutton, G. H. 1980. Glucuronidation of drugs and other compounds. CRC Press, Boca Raton, FL.

2. Crigler, J. F., and V. A. Najjar. 1952. Congenital familial nonhemolytic jaundice with kernicterus. Pediatrics. 10:169-180.
3. Wolkoff, A. W., J. Roy Chowdhury, and I. M. Arias. 1983. Hereditary jaundice and disorders of bilirubin metabolism. In The Metabolic Basis of Inherited Disease. J. B. Stanbury, J. B. Wijngaarden, D. S. Frederickson, J. L. Goldstein, and M. S. Brown, editors. McGraw Hill Book Co., New York. 1385-1420.

4. Jansen, P. L. M., and R. P. J. Oude Elferink. 1988. Hereditary hyperbilirubinemias: a molecular and mechanistic approach. Semin. Liver Dis. 8:168-178.

5. Weatherill, P. J., S. M. E. Kennedy, and B. Burchell. 1980. Immunochemical comparison of UDP-glucuronyltransferase from Gunn- and Wistar-rat livers. Biochem. J. 191:155-163.

6. Coughtrie, M. W. H., B. Burchell, S. R. P. Shepherd, and J. R. Bend. 1987. Defective induction of phenol glucuronidation by 3 methylcholantrene in Gunn rats is due to the absence of a specific UDP-glucuronyltransferase isoenzyme. Mol. Pharmacol. 31:585-591.

7. Watkins, J. B., and C. D. Klaassen. 1982. Induction of UDPglucuronosyltransferase activities in Gunn, heterozygous, and Wistar rat livers by pregnenolone-16 $\alpha$-carbonitrile. Drug Metab. Dispos. 10:590-594.

8. Burchell, B., M. H. W. Coughtrie, M. R. Jackson, S. R. P. Shepherd, D. Harding, and R. Hume. 1987. Genetic deficiency of bilirubin glucuronidation in rats and humans. Mol. Aspects Med. 9:429-455.

9. Wishart, G. J. 1978. Functional heterogeneity of UDP-Glucuronosyltransferase as indicated by its differential development and inducibility by glucocorticoids. Biochem. J. 174:485-489.

10. Wishart, G. J. 1978. Demonstration of functional heterogeneity of hepatic uridine diphosphate glucuronosyltransferase activities after administration of 3-methylcholantrene and phenobarbital to rats. Biochem. J. 174:671-672.

11. Lilienblum, W., A. K. Walli, and K. W. Bock. 1982. Differential induction of rat liver microsomal UDP-glucuronosyltransferase activities by various inducing agents. Biochem. Pharmacol. 31:907913.

12. Falany, C. N., and T. R. Tephly. 1983. Separation, purification and characterization of three isoenzymes of UDP-glucuronyltransferase from rat liver microsomes. Arch. Biochem. Biophys. 227:248-258.

13. Roy Chowdhury, J., N. Roy Chowdhury, C. N. Falany, T. R. Tephly, and I. M. Arias. 1986. Isolation and characterization of multiple forms of rat liver UDP-glucuronate glucuronosyltransferase. Biochem. J. 233:827-837.

14. Falany, C. N., M. D. Green, E. Swain, and T. R. Tephly. 1986. Substrate specificity and characterization of rat liver p-nitrophenol, $3 \alpha$-hydroxysteroid and $17 \beta$-hydroxysteroid UDP-glucuronosyltransferases. Biochem. J. 238:65-73.

15. Puig, J. F., and T. R. Tephly. 1986. Isolation and purification of rat liver morphine UDP-glucuronosyltransferase. Mol. Pharmacol. 30:558-565.

16. Von Meyerinck, L., B. L. Coffman, M. D. Green, R. B. Kirkpatrick, A. Schmoldt, and T. R. Tephly. 1985. Separation, purification, and characterization of digitoxigenin-monodigitoxoside UDPglucuronosyltransferase activity. Drug Metab. Dispos. 13:700-704.

17. Jackson, M. R., and B. Burchell. 1986. The full length coding sequence of rat liver androsterone UDP-glucuronyltransferase cDNA and comparison with other members of this gene family. Nucleic Acids Res. 14:779-795.

18. Mackenzie, P. I. 1986. Rat liver UDP-glucuronosyltransferase: sequence and expression of a cDNA encoding a phenobarbital inducible form. J. Biol. Chem. 261:6119-6125.

19. Mackenzie, P. I. 1986. Rat liver UDP-glucuronosyltransferase: cDNA sequence and expression of a form glucuronidating 3-hydroxyandrogens. J. Biol. Chem. 261:14112-14117.

20. Mackenzie, P. I. 1987. Rat liver UDP-glucuronyltransferase: identification of cDNAs encoding two enzymes which glucuronidate testosterone, dihydrotestosterone and $\beta$-estradiol. J. Biol. Chem. 262:9744-9749.

21. Irshaid, Y. M., and T. R. Tephly. 1987. Isolation and purifica- 
tion of two human liver UDP-glucuronyltransferases. Mol. Pharmacol. 31:27-34.

22. Jackson, M. R., L. R. McCarthy, D. Harding, S. Wilson, M. W. H. Coughtrie, and B. Burchell. 1987. Cloning of a human liver microsomal UDP-glucuronosyltransferase cDNA. Biochem. J. 242:581-588.

23. Harding, D., S. Fournel-Gigleux, M. Jackson, and B. Burchell. 1988. Cloning and substrate specificity of a human phenol UDP-glucuronosyltransferase expressed in COS-7 cells. Proc. Natl. Acad. Sci. USA. 85:8381-8385.

24. Miners, J. O., K. J. Lillywhite, A. P. Matthews, M. E. Jones, and D. J. Birkett. 1988. Kinetic and inhibitor studies of 4-methylumbelliferone and 1-naphtol glucuronidation in human liver microsomes. Biochem. Pharmacol. 37:665-671.

25. Friedman, F. K., R. C. Robinson, S. S. Park, and H. V. Gelboin. 1983. Monoclonal antibody directed immunopurification and identification of cytochromes P-450. Biochem. Biophys. Res. Commun. 116:859-865.

26. Peters, W. H. M., W. A. Allebes, P. L. M. Jansen, L. G. Poels, and P. J. A. Capel. 1987. Characterization and tissue specificity of a monoclonal antibody against human uridine 5 '-diphosphate-glucuronyltransferase. Gastroenterology. 93:162-169.

27. Peters, W. H. M., and P. L. M. Jansen. 1987. Immunocharacterization of UDP-Glucuronyltransferase isoenzymes in human liver, intestine and kidney. Biochem. Pharmacol. 37:564-567.

28. Rao, G. S., G. Haueter, M. L. Rao, and H. Breuer. 1976. An improved assay for steroid glucuronyltransferase in rat liver microsomes. Anal. Biochem. 74:35-40.

29. Burchell, B. 1981. Bilirubin UDP-glucuronyltransferase Methods Enzymol. 62:188-192.

30. Leakey, J. E. A. 1978. An improved assay for uridine diphosphate glucuronosyltransferase activity towards 5-hydroxytryptamine and some properties of the enzyme. Biochem. J. 175:1119-1124.

31. Williams, C. H., and H. Kamin. 1962. Microsomal triphosphopyridine nucleotide cytochrome c reductase of liver. J. Biol. Chem. 237:587-595.

32. Bradford, M. 1976. A rapid and sensitive method for the quantitation of microgram quantities of protein utilizing the principle of protein-dye binding. Anal. Biochem. 72:248-253.

33. Laemmli, U. K. 1970. Cleavage of structural proteins during the assembly of the head of bacteriophage T4. Nature (Lond.). 227:680-685.

34. Towbin, H., T. Staehlin, and J. Gordon. 1979. Electrophoretic transfer of proteins from polyacrylamide gels to nitrocellulose sheets: procedure and some applications. Proc. Natl. Acad. Sci. USA. 76:4350-4354.

35. Blake, M. S., K. H. Johnston, G. J. Russell-Jones, and E. C. Gotschlich. 1984. A rapid, sensitive method for detection of alkaline phosphatase conjugated anti-antibody on western blots. Anal. Biochem. 136:175-179.

36. Jansen, P. L. M., and I. M. Arias. 1975. Delipidation and reactivation of UDP-Glucuronyltransferase from rat liver. Biochim. Biophys. Acta. 391:28-38.

37. Wood, G. C., G. Scott, and A. B. Graham. 1985. Phospholipid regulation of UDP-glucuronyltransferase. In Advances in Glucuronide Conjugation. S. Matern, K. W. Bock, and W. Gerok, editors. Falk Symp. 40:83-91.

38. Abe, N., E. Abe, and A. Yuasa. 1988. Purification and properties of 5-hydroxytryptamine UDP-glucuronyltransferase from rat liver microsomes. J. Biochem. 104:421-426.

39. Leakey, J. E. A. 1984. Development of hepatic UDP-glucuronyltransferase activities in rats and rhesus monkeys. In Advances in Glucuronide Conjugation. S. Matern, K. W. Bock, and W. Gerok, editors. Falk Symp. 40:111-117.

40. Leakey, J. E. A., R. Hume, and B. Burchell. 1987. Development of multiple activities of UDP-glucuronyltransferase in human liver. Biochem. J. 243:859-861.

41. Amor, M., K. L. Parker, H. Globerman, M. I. Nem, and P. C. White. 1988. Mutation in the CY21B gene (Ile-172>Asn) causes steroid 21-hydroxylase deficiency. Proc. Natl. Acad. Sci. USA. 85:16001604.

42. Higashi, Y., A. Tanae, H. Inoue, and Y. Fujii-Kuriyama. 1988. Evidence for frequent gene conversion in the steroid 21-hydroxylase P-450 (C21) gene: implications for steroid 21-hydroxylase deficiency. Am. J. Hum. Genet. 42:17-25.

43. Kimura, H., K. Sogawa, Y. Sakai, and Y. Fujii-Kuriyama. 1989. Alternative splicing mechanism in a cytochrome P-450 (P-450PB-1) gene generates the two mRNAs coding for proteins of different functions. J. Biol. Chem. 264:2338-2342. 